F. Reprod. Fert. (1967) 14, 465-468

BRIEF COMMUNICATION

\title{
ABNORMAL FERTILIZATION OF RAT EGGS AFTER INJECTION OF SUBSTANCES INTO THE AMPULLAE OF THE FALLOPIAN TUBES
}

\author{
SANDRA M. VON DER BORCH* \\ Department of Physiology, Cambridge, England \\ (Received 26th September 1966, revised 14th Fune 1967)
}

\begin{abstract}
Summary. The fertilization of rat eggs after various treatments of, or the injection of various substances into, the Fallopian tubes just before fertilization was studied. After all treatments, an increase was observed in the number of eggs which contained supplementary spermatozoa and in the numbers of supplementary spermatozoa per egg. Most treatments produced a small number of eggs in which a second spermatozoon entered the vitellus later than the first, and these eggs were said to be 'refertilized'. Several other abnormalities were produced by the treatments.
\end{abstract}

After the injection of $1 \mu \mathrm{l}$ of $\mathrm{M} / 500$ versene into the ampullae of Sherman rats $2 \frac{1}{2}$ to $3 \mathrm{hr}$ after mating, Piko (1961) found that $46.2 \%$ of the eggs recovered 20 to $50 \mathrm{hr}$ later had supplementary spermatozoa in the perivitelline space, compared with $22.6 \%$ of control eggs. Moreover, in $9 \%$ of these eggs 'refertilization' had occurred.

In the present paper 'refertilization' is taken to mean that appearances indicated a second and later sperm entry. The work of Piko was repeated and experiments were carried out to test the specificity of versene in the refertilization phenomenon. The effects of various solutions were tested and observations were also made on eggs collected from untouched ampullae (the untouched control series), from ampullae into which a needle had been inserted without injection and from ampullae which had been withdrawn through the opening in the body wall and replaced. Hooded rats were used, fed on Oxoid 41B rat pellets and kept under $14 \mathrm{hr}$ of light by controlled lighting. They were mated between 08.30 and 09.30 hours; this results in delayed mating' as described by Austin \& Braden (1954a), who showed that sperm penetration occurred 2 to $6 \mathrm{hr}$ later. Immediately after mating various experiments (see Table 1) were carried out under ether anaesthesia which lasted less than $5 \mathrm{~min}$ and therefore precluded the danger of parthenogenic effects from the anaesthesia (Austin \& Braden, 1954b). The ovarian capsule was

* Present address: Department of Obstetrics and Gynaecology, The Queen Elizabeth Hospital, Woodville, South Australia. 


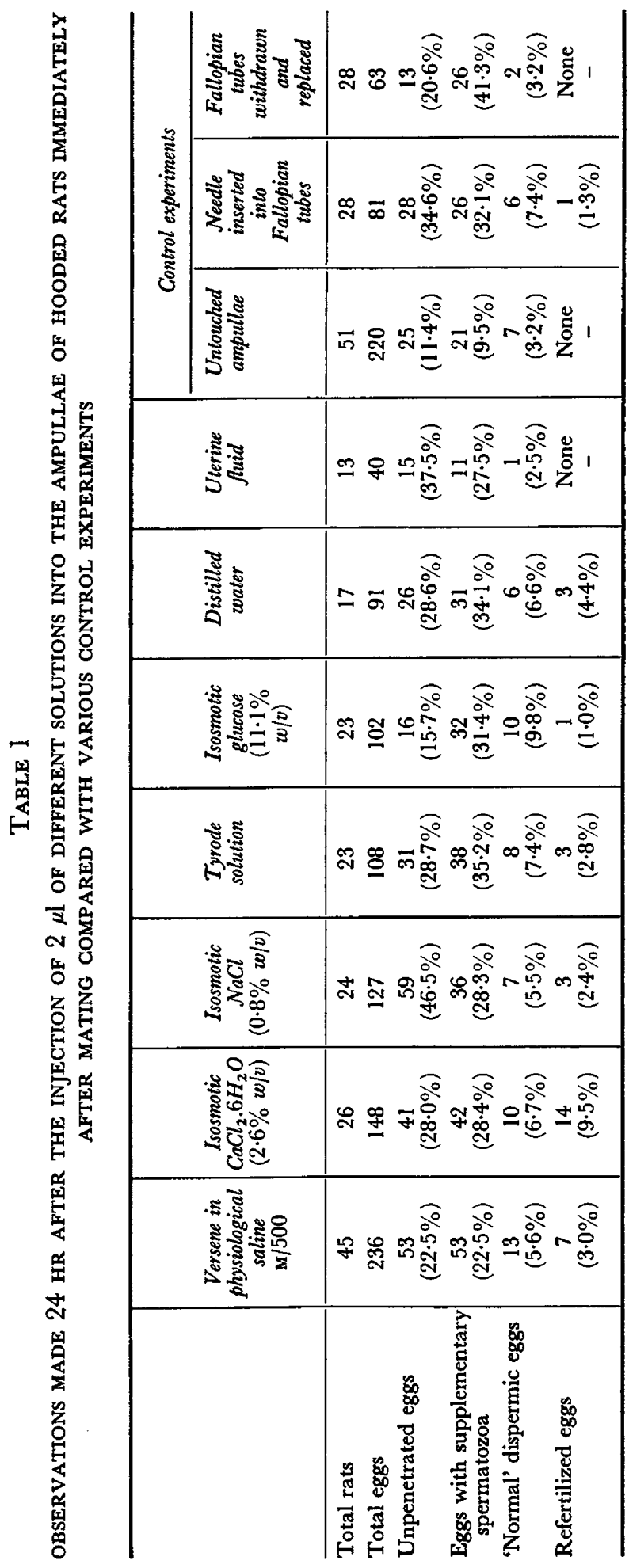


punctured with a $\frac{1}{2}$ in. 17 gauge needle to allow injection into the ampulla. Eggs were recovered $24 \mathrm{hr}$ later and their manipulation was as described by Austin (1961).

From Table 1 it can be seen that injection of all substances (except uterine fluid, which was only tried in a small series) induced between 1.0 and $9.5 \%$ refertilization. There was a marked increase in numbers of eggs with supplementary spermatozoa in the perivitelline space and in the numbers of supplementary spermatozoa compared with the untouched controls (Table 2). A general increase in the incidence of 'normal' dispermic eggs was also found which probably resulted from excess spermatozoa in the perivitelline space at the time of penetration. Both male pronuclei in these eggs appeared to be at the same stage of their development, thus the term 'normal' dispermic is used to describe these eggs. Mechanical disturbance of the environment probably caused the increase of unpenetrated eggs after various treatments.

TABLE 2

SAMPLE DISTRIBUTION OF SUPPLEMENTARY SPERMATOZOA IN EGGS FROM UNTOUCHED AND TREATED AMPULLAE OF THE RAT

\begin{tabular}{|c|c|c|c|c|c|c|c|}
\hline & \multirow{2}{*}{$\begin{array}{l}\text { Total } \\
\text { eggs }\end{array}$} & \multicolumn{6}{|c|}{ No. of supplementary spermatozoa } \\
\hline & & 1 & 2 & 3 & 4 & 5 & 6 to 10 \\
\hline $\begin{array}{l}\text { Eggs from untouched ampullae } \\
\text { Eggs from treated ampullae }\end{array}$ & $\begin{array}{l}30 \\
30\end{array}$ & $\begin{array}{l}25 \\
13\end{array}$ & $\begin{array}{l}4 \\
6\end{array}$ & $\begin{array}{l}1 \\
5\end{array}$ & $\begin{array}{l}0 \\
3\end{array}$ & $\begin{array}{l}0 \\
1\end{array}$ & $\begin{array}{l}0 \\
2\end{array}$ \\
\hline
\end{tabular}

Commonly a refertilized egg contained two or more sperm tails, and toluidine blue staining showed a normal first cleavage metaphase group of chromosomes and one or more dark oval masses, as described by Piko. The dark masses were also found in stained eggs with normal male and female pronuclei, but with an extra sperm tail in the vitellus. After staining, eggs became detached from the glass and irregular surfaces prevented satisfactory photography. The darkly staining masses were presumably chromatin material from the degenerating heads of refertilizing spermatozoa. Occasionally the additional sperm head was enclosed in a curious vacuole (Pl. 1, Fig. 1).

Other abnormalities were observed after various treatments. Several eggs were unpenetrated although there were spermatozoa in the perivitelline space. In five of forty eggs observed after uterine fluid treatment, the tail of the fertilizing spermatozoon was only partly incorporated into the vitellus, although normal pronuclear development was proceeding (Pl. 1, Fig. 2). Subnuclei were found in about 3\% of fertilized eggs after all the treatments except versene. The formation of subnuclei is an indication of abnormal development and was reported by Austin \& Braden (1954b) after many different treatments of rodent eggs.

Both mock treatments caused an increase in eggs with supplementary spermatozoa compared with controls, and one refertilized egg was found in this small series. Alteration of temperature, $\mathrm{pH}$ or oxygen tension had probably occurred. 
These results suggest that a delicate balance of factors is essential for normal fertilization reactions to proceed. The refertilization phenomenon is influenced by various factors, although these different factors may all operate by producing the same effect, such as an alteration in calcium balance in the plasma membrane.

This work was supported by grants from the Ford Foundation, the Population Council, and by a Commonwealth Scholarship. I would like to thank $\mathrm{Dr}$ C. R. Austin and Professor A. S. Parkes for their help and encouragement.

\section{REFERENCES}

Austin, C. R. (1961) The mammalian egg. Blackwell Scientific Publications, Oxford.

Austin, C. R. \& Braden, A. W. H. (1954a) Time relations and their significance in the ovulation and penetration of eggs in rats and rabbits. Aust. 7. biol. Sci. 7, 179.

Austin, C. R. \& BRADEN, A. W. H. (1954b) Induction and inhibition of the second polar division in the rat egg, and subsequent fertilization. Aust. F. biol. Sci. 7, 195.

Piко, L. (1961) Repeated fertilization of fertilized rat eggs after treatment with Versene (EDTA). Am. Zoologist, 1, 467. 
PI ATE 1
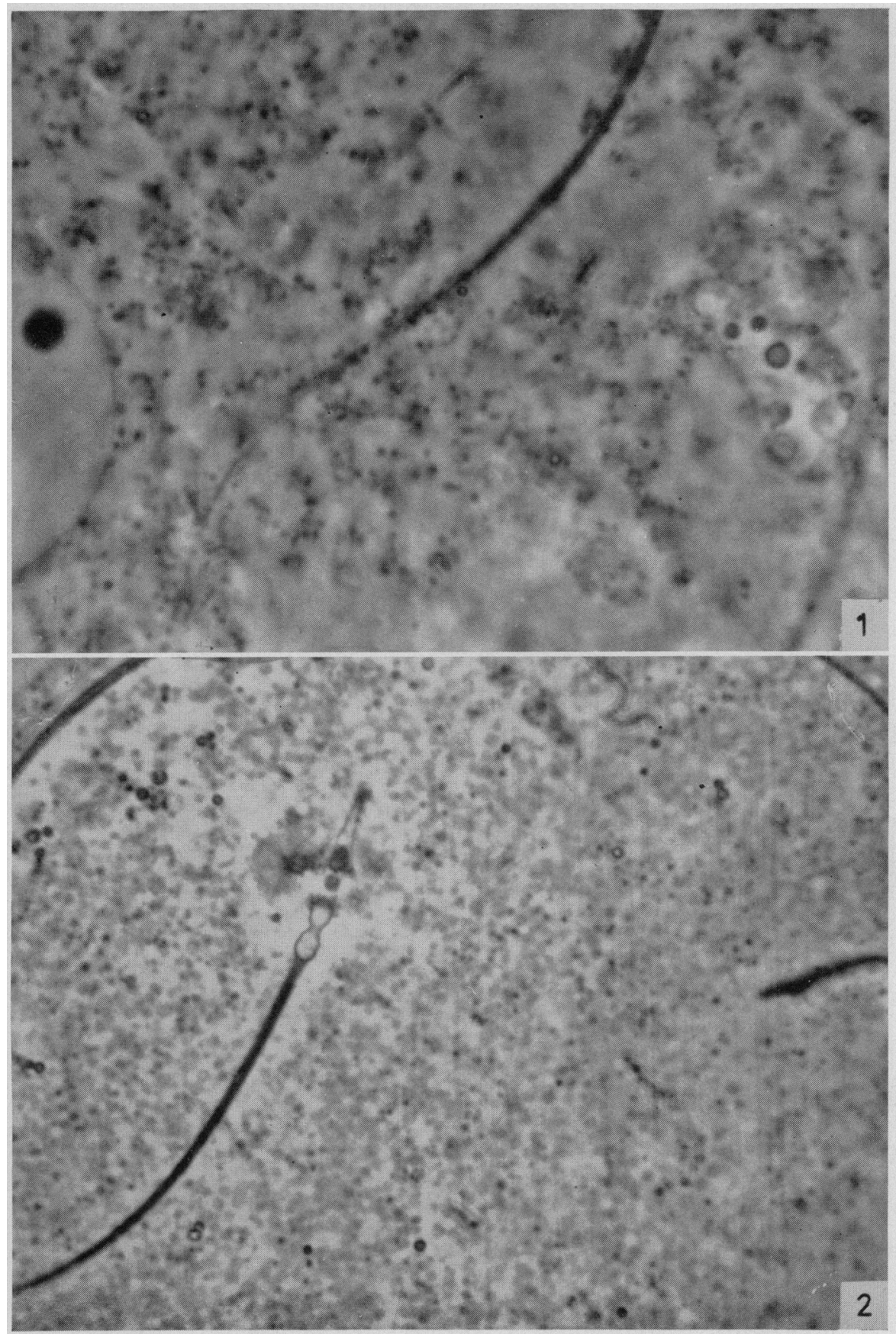

FIG. 1. Part of an egg refertilized after treatment with distilled water. This egg contained three sperm tails, indicating the entry of three spermatozoa. This figure shows one of two male pronuclei of equal size which were present in the vitcllus, two of the three sperm tails and, on the right-hand side, an abnormal vacuole-like 'pronucleus'. There was also a small female pronucleus.

Fig. 2. Abnormal development of the head of a spermatozoon which was only partially incorporated into the vitellus of an egg after treatment with uterine fluid. 